\title{
A FRAMEWORK FOR CONDUCTING AN EXTERNAL STRATEGIC MANAGEMENT AUDIT
}

\author{
Fred R. David
}

Department of Management

Mississippi State University

Mississippi State, Mississippi

The strategic management process can be viewed to consist of three basic stages: strategy formulation, strategy implementation, and strategy evaluation (3). The strategy formulation stage includes activities such as performing an internal audit, conducting an external audit, developing a clear business mission, establishing objectives, and devising strategies. An external audit identifies and evaluates economic, social, political, technological, and competitive trends and events that impact an organization's strategic position (16). Firms should strive to pursue strategies that capitalize upon external opportunities and avoid the impact of external threats (5). The existence and magnitude of environmental changes today underlie the need for an effective external audit (7). Two new analytical tools called the Competitive Profile Matrix (CPM) and the External Factor Evaluation Matrix (EFEM) are presented and exemplified in this article (4). A five-step approach for conducting an external audit is recommended as follows:

I. Isolate key environmental variables

II. Isolate key sources of environmental information

III. Develop appropriate forecasts

IV. Construct a Competitive Profile Matrix

V. Construct an External Factor Evaluation Matrix (3).

\section{Isolate Key Environmental Variables}

The first step in performing an external audit is to isolate key variables in a firm's environment. Key variables to be monitored typically vary widely depending on a company's situation and industry. Environmental variables can be categorized into five major groups: (1) economic, (2) social, cultural, demographic, and geographic, (3) political, governmental, and legal, (4) technological, and (5) competitive. Relationships among key environmental variables and an organization are depicted in Exhibit 1. 


\section{Exhibit 1: Relationships among Key Environmental}

\section{Variables and a Firm}

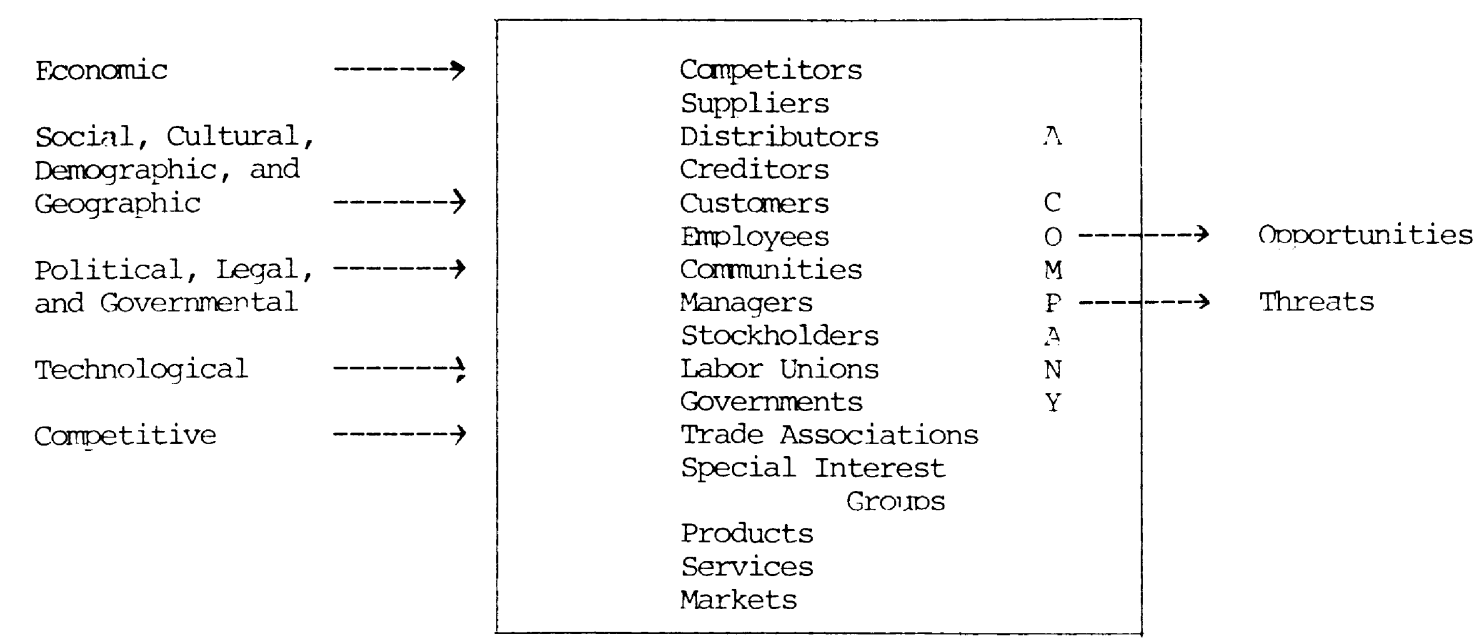

Changes in environmental variables translate into changes in consumer demand for industrial and consumer products and services. Environmental forces affect the types of products developed, the nature of positioning and market segmentation strategies, the types of services offered, and the choice of businesses to acquire or sell. Identifying and evaluating environmental opportunities and threats enables a company to formulate or reformulate its basic mission, to design strategies to achieve its objectives, and to develop policies to achieve its goals (1).

Economic variables can have a direct impact on the potential attractiveness of various company strategies. For example, as interest rates rise, individuals' discretionary income declines, which lowers the demand for discretionary goods. Other economic variables such as the availability of credit, the level of disposable income, inflation rates, federal government budget deficits, consumption patterns, unemployment trends, the value of the dollar in world markets, import/export factors, price fluctuations, monetary policies, fiscal policies, and tax rates often represent key opportunities and threats for organizations.

Social, cultural, demographic, and geographic changes can also have a dramatic affect upon a firm's products, services, markets, and customers $(2,9)$. In virtually every aspect of life, the United States is much different in the 1980's than it was in the 1970's, and the 1990's promise even greater changes. Social changes are creating a different type of consumer and consequently a need for different products, different services, and different company strategies. A maturing American society is resulting in new products, services, markets, and personnel policies as well as a new look in advertising, a decreased emphasis on schools, an increased emphasis on health care, a growing market for luxury items, and a drop in crime rates. The aging and geographically shifting U.S. population affects the strategic orientation of nearly every organization. 
Political, governmental, and legal variables can represent key opportunities and threats for both small and large organizations. Federal, state, and local governments are a major regulator, deregulator, subsidizer, employer, and customer of organizations in the United States. For industries and firms that depend heavily on government contracts or subsidies, political forecasts can be the most important part of an external audit. Changes in patent laws, antitrust legislation, and lobbying activities can significantly impact firms. The increasing global interdependence among economies, markets, governments, and organizations makes it imperative that firms of all sizes consider the possible impact of political variables on the formulation and implementation of competitive strategies. Frederick Gluck (8) concludes that a world market is emerging from what previously was a multitude of distinct national markets. In an industry that is or is rapidly becoming global, the riskiest possible posture for a domestic firm may be to remain a domestic competitor.

Technological variables can dramatically affect an organization's products, services, markets, suppliers, distributors, competitors, customers, manufacturing processes, marketing practices, and competitive position $(15,10,13)$. Technological advancements can create new markets, result in a proliferation of new and improved products, change the relative competitive cost positions in an industry, render existing products and services obsolete, collapse or merge previously separate businesses by reducing or eliminating cost barriers, create shorter production runs, create shortages in technical skills, and result in changing values and expectations of employees, managers, and customers. Technological advancements can create new competitive advantages that are more powerful than existing advantages. No company or industry today is insulated against emerging technological developments. In high-tech industries, identification and evaluation of key technological opportunities and threats can be the most important part of an external strategic management audit. As an example, electronic greeting cards were introduced in 1984 and performed relatively simple feats like beeping Jingle Bells and humming Joy to the World. For Christmas 1985, a new generation of cards will play complex melodies, blink lights, and even wish recipients Christmas greetings in a real voice. The new technology for these cards is coming from the Far East. The big three in this industry, Hallmark Cards, American Greetings, and Gibson Greeting Cards, are making substantial investments in new technologies, including laser printing and holography. Hallmark is presently constructing a \$20 million dollar Technology and Innovation Center to take advantage of technological opportunities.

Finally, competitive variables are critically important in performing an external audit. They focus on rival firms' strengths, weaknesses, capabilities, opportunities, threats, objectives, goals, and strategies. Collecting and evaluating competitive information is essential to performing an external audit effectively. The more information and knowledge a firm can obtain 
about each of its major competitors, the more likely it can formulate and implement effective strategies. Major competitors' weaknesses can represent external opportunities; major competitors' strengths could represent key threats.

Top managers could isolate key variables by conducting a comprehensive study to determine what environmental factors have affected their industry most in the past. This information would provide a basis for isolating key variables to monitor in the future. The number and complexity of key variables to be monitored would depend on a particular firm's industry, size, location, and competitive position. However, a set of five to twenty environmental variables should be isolated as being most important for monitoring in the future. An effective technique for isolating the most important variables form a list of many factors is nominal grouping. Nominal grouping is a process whereby individuals rank order key factors and then collectively decide which variables are most important.

\section{Isolate Key Sources Of Environmental Information}

The second step in performing an external audit is to isolate key sources of environmental information. A wealth of strategic information is available to organizations from both published and nonpublished sources $(6,16)$. Environmental information can be obtained through nonpublished sources such as customer surveys, market research, speeches at professional meetings, conversations with stockholders, interviews, and aerial photographs. Published sources of strategic information include periodicals, journals, reports, government documents, abstracts, books, directories, and manuals. To access published sources of information effectively, a number of indexes can be used to locate strategic information by subject, topic, source, author, company, and industry. Indexes such as the F\&S Index, the Wall Street Journal/Barrons Index, and the Business Periodicals Index can save a considerable amount of time and effort identifying and evaluating environmental opportunities and threats. Some important published sources of environmental information are provided in Exhibit 2.

\section{Exhibit 2: Sources of Environmental Information}

Statistical Abstract of the U.S.

Survey of Business

Business Conditions Digest

Survey of Buying Power

Federal Register

Scientific and Technical Information Source

U.S. Industrial Outlook

Value Line Investment Survey

Moody's Industrial Manual

Moody's Bank and Finance Manual
Standard and Poor's Corporation.

Fortune

Dun's Business Month

Industry Week

Business Week

Barrons

Forbes

The Wall Street Journal

Facts on File

The Wall Street Transcript

Note: This is not an exhaustive list of useful sources. 


\section{Develop Appropriate Forecasts}

Once key environmental variables have been selected and specific sources of information have been located, the third step in performing an external strategic management audit is to forecast key environmental variables. Forecasts are educated assumptions about future trends and events. Forecasting is a complex activity due to many interrelated factors such as changes in political situations, technological innovations, changes in cultures, new products, improved services, stronger competitors, shifts in government priorities, changing social values, unstable economic conditions, and unforeseen events. Forecasting is so complex that many strategists rely upon published environmental forecasts to effectively identify key environmental opportunities and threats (12).

Many publications regularly forecast environmental variables, including $I n$ dustry Week's Trends and Forecasts, Business Week's Investment Outlook, Standard \& Poor's Earnings Forecaster, and the U.S. Industrial Outlook. The reputation and viability of these publications depends to some extent upon accurate forecasts, so published sources of information can offer the best projections available for some variables. When published forecasts of key internal or external variables are not available, organizations must develop their own projections. Most organizations forecast their own revenues and profits, and sometimes must generate other forecasts such as market share or customer loyalty information in local areas.

Forecasting tools can be broadly categorized into two groups: quantitative techniques and qualitative techniques (14). There are three basic types of quantitative forecasting techniques: econometric models, regression, and trend extrapolation. Econometric models are based on simultaneous systems of regression equations. With the advent of sophisticated computers, econometric models have become the most widely used approach for forecasting economic variables. Single and multiple regression is a statistical technique that explains variations in a dependent variable by changes in one or more independent variables. Trend extrapolation is simply projecting past trends into the future. It is important to note that all quantitative forecasts, regardless of statistical sophistication and complexity, are based on historical relationships among key variables. Linear regression, for example, is based on the assumption that the future will be just like the past - which it never is. Forecasting tools must be used carefully or the results can be more misleading than helpful. As historical relationships become less stable, quantitative forecasts become less accurate.

Qualitative forecasts are most appropriate when historical data is not available and when the relationships among key variables are not expected to continue in the future. There are six basic qualitative approaches to forecasting future environmental conditions: (1) salesforce estimate, (2) juries of executive opinion, (3) anticipatory surveys or market research, (4) scenario forecasts, (5) delphi forecasts, and (6) brainstorming. Too often in qualitative forecasting, managers are guilty of "predicting" what they would like to occur.

No forecast is perfect and some forecasts are even wildly inaccurate. This fact accents the need for strategists to devote sufficient time and effort to study the 
underlying bases for published forecasts and to develop internal forecasts of their own. Key external opportunities and threats can be effectively identified through good forecasts. Accurate forecasts can provide major competitive advantages for organizations. Forecasts are vital to the strategic management process and to the success of organizations.

\section{Construct A Competitive Profile Matrix}

Of all the environmental trends and events that can affect a firm's strategic position, competitive forces are often considered to have the greatest impact (17). For this reason, step four in performing an external audit is to construct a Competitive Profile Matrix (4). This analytical tool identifies a firm's major competitors and tells where the rival firms are particularly strong and weak. The procedures required to develop a Competitive Profile Matrix are given below:

1. Identify key success factors in the industry.

2. Assign a weight to each key success factor to indicate the relative importance of that factor to success in the industry. Weights range from 0.0 (not important) to 1.0 (very important). They apply to all competitors and must sum to 1.0.

3. Assign a rating to each competitor to indicate that firm's strength or weakness on each key success factor, where 1 = major weakness, $2=$ minor weakness, $3=$ minor strength, and $4=$ major strength.

4. Multiply the weight assigned to each key success factor by the corresponding rating for each competitor to determine a weighted score for each firm. The weighted score indicates the relative strength or weakness of each competitor on each key success factor.

5. Sum the weighted score column for each competitor. Total weighted scores in a Competitive Profile Matrix reveal the relative overall strength of the major competitors in an industry. The highest total weighted score indicates the strongest competitor while the lowest total weighted score corresponds to the weakest firm. The total weighted score could range from 1.0 (lowest) to 4.0 (highest), with 2.5 being the average.

An example Competitive Profile Matrix is given in Exhibit 3. The example illustrates that customer service, price, product quality, technological superiority, dealer relations, financial strength, and advertising effectiveness are key success factors in the personal computer industry. The rating scores of 4 suggest that Company 1 is strongest in customer service, dealer relations, and advertising effectiveness; Company 2 is strongest in price competitiveness, and Company 3 is strongest in technological superiority and financial strength. Company 3 is weak in price competitiveness (rating $=2$ ), while Company 2 is weak in two areas, financial strength and advertising effectiveness. Based on this example, Company 1 is the strongest competitor in 
the personal computer industry, with a total weighted score of 3.41 , followed by Company 3 and Company 2 with scores of 3.01 and 2.91 respectively.

A Competitive Profile Matrix for Winnebago Industries, Inc. is provided in Exhibit 4. Note that two competing firms, Fleetwood and Coachman, have surpassed Winnebago as leaders in the motor home industry.

\section{Exhibit 3: A Sample Competitive Profile Matrix}

$\begin{array}{ll}\text { Key Success Factor } & \\ & \text { Weight } \\ & .22 \\ \text { Customer Service } & .20 \\ \text { Price } & .18 \\ \text { Product Duality } & .11 \\ \text { Technological } & \\ \text { Superiority } & \\ \text { Dealer Relations } & .10 \\ \text { Financial Strength } & .10 \\ \text { Advertising } & .09 \\ \text { Effectiveness } & 1.00 \\ \text { TOTAL WEIGlitED SCORES }\end{array}$

\begin{tabular}{cr}
\multicolumn{2}{c}{ Company 1 } \\
Rating & $\begin{array}{c}\text { weighted } \\
\text { Score }\end{array}$ \\
4 & .88 \\
3 & .60 \\
3 & .54 \\
3 & .33 \\
4 & .40 \\
3 & .30 \\
4 & .36 \\
& \\
& .41
\end{tabular}

\begin{tabular}{cr}
\multicolumn{2}{r}{ Company 2 } \\
Rating & $\begin{array}{r}\text { Weight } \\
\text { Score }\end{array}$ \\
3 & .66 \\
4 & .80 \\
3 & .54 \\
3 & .33 \\
3 & .30 \\
2 & .20 \\
2 & .18 \\
& \\
& \\
&
\end{tabular}

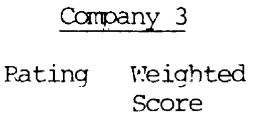

.66

.40

.54

.44

.20

.40

.27

2.91

\section{Exhibit 4: A Competitive Profile Matrix For Winnebago Industries}

$\begin{array}{lr}\text { Key Success Factor } & \\ & \text { Weight } \\ \text { Sales Volume } & .15 \\ \text { Level of R\&D } & .14 \\ \text { Expenditures } & \\ \text { Net Profit Margin } & .14 \\ \text { Promotion } & .11 \\ \text { Effectiveness } & \\ \text { Market Share } & .14 \\ \text { Technology } & .10 \\ \text { Advertising } & .10 \\ \text { Location } & .07 \\ \text { Product Suality } & .05 \\ & 1.00 \\ \text { TorAL WEIGHTED SCORES }\end{array}$

\begin{tabular}{|c|c|}
\hline \multicolumn{2}{|c|}{ Winnebago } \\
\hline Rating & $\begin{array}{l}\text { Weight } \\
\text { Score }\end{array}$ \\
\hline 2 & .30 \\
\hline 4 & .56 \\
\hline 4 & .56 \\
\hline 2 & .22 \\
\hline 3 & .42 \\
\hline 4 & .40 \\
\hline 2 & .20 \\
\hline 2 & .14 \\
\hline 3 & .15 \\
\hline
\end{tabular}

\begin{tabular}{cr}
\multicolumn{2}{r}{ Fleetwood } \\
Pating & $\begin{array}{r}\text { Weight } \\
\text { Score }\end{array}$ \\
4 & .60 \\
3 & .42 \\
3 & .42 \\
4 & .44 \\
4 & .56 \\
3 & .30 \\
3 & .30 \\
3 & .21 \\
4 & .20 \\
& \\
& 3.55 \\
\hline
\end{tabular}

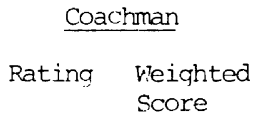

$\underline{2.95}$
.45

.42

.33

.42

.30

.40

.28

.15

3.07

In developing a Competitive Profile Matrix, strategists should utilize objective information as much as possible in choosing key factors, deciding on appropriate weights, and assigning ratings. However, subjective judgments are always necessary, so this analytical tool should not be used 
indiscriminately in making decisions. A Competitive Profile Matrix answers the following key questions about a firm:

1. Who are our major competitors?

2. What key factors are most important to being successful in the industry?

3. What is the relative importance of each key factor to success in the industry?

4. To what extent is each competitor strong or weak on each key success factor (where $1=$ major weakness, $2=$ minor weakness, $3=$ minor strength, and $4=$ major strength)?

5. Overall, how strong or weak is each major competitor.

\section{Construct An External Factor Evaluation Matrix}

The final step in conducting an external strategic management audit is to construct an External Factor Evaluation Matrix (4). Presented for the first time in this article, this analytical tool is offered as an effective way to summarize and evaluate environmental opportunities and threats. The procedures required to construct an External Factor Evaluation Matrix (EFEM) are given below:

1. List the firm's key opportunities and threats.

2. Assign a weight that ranges from 0.0 (not important) to 1.0 (very important) to each factor. The weight assigned to a given factor indicates the relative importance of that factor to success in a given industry. The summation of all weights assigned to the factors must total 1.0 .

3. Assign a one to four rating to each factor to indicate whether that variable represents a major threat (rating $=1$ ), a minor threat (rating $=2$ ), a minor opportunity (rating $=3$ ), or a major opportunity (rating $=4)$ to the organization.

4. Multiply each factor's weight by its rating to determine a weighted score for each variable.

5. Sum the weighted scores for each variable to determine the total weighted score for an organization.

Regardless of the number of key opportunities and threats that are included in an EFEM, the highest possible total weighted score for an organization is 4.0 and the lowest possible total weighted score is 1.0. The average total weighted score is therefore 2.5. A total weighted score of 4.0 would indicate that an organization competes in an attractive industry and has abundant external opportunities, while a total score of 1.0 would characterize an organization that competes in an unattractive industry and faces severe external threats. The recommended number of key opportunities and 
threats to include in an EFEM is from five to twenty. An External Factor Evaluation Matrix answers four basic questions:

1. What are the firm's environmental opportunities and threats?

2. What is the relative importance of each key opportunity and threat to success in the industry?

3. Does each key factor represent a major threat (rating $=1$ ), a minor threat (rating $=2$ ), a minor opportunity (rating $=3$ ), or a major opportunity (rating $=4$ ).

4. What is the firm's total weighted score resulting from the external factor evaluation? Is the score above or below the average of 2.5 ?

An example of EFEM is provided in Exhibit 5. Note that government deregulation is the most important environmental factor affecting this industry. The sample firm has two major opportunities, "population shift to the American West" and "computerized information systems". The sample organization has one major threat, "rising interest rates." The total weighted score of 2.7 indicates that the sample firm competes in an industry that is just above average in overall attractiveness.

\section{Exhibit 5: A Sample External Factor Evaluation Matrix}

Key External Factor

Rising interest rates

Population shift to the American West

Government deregulation

A major competitor's expansion strategy

Computerized information system Total

\begin{tabular}{c} 
Weight \\
.20 \\
.10 \\
.30 \\
.20 \\
.20 \\
\hline 1.00
\end{tabular}

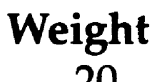

.10

30

20 $\underset{1}{\text { Rating }}$

4

3

2

4
Weighted Score .20

.40

.90

.40

$\frac{.80}{2.70}$

An EFEM is provided in Exhibit 6 for Dresser Industries. Dresser is a three billion dollar energy company with over 40,000 employees. Such a large firm obviously faces many external opportunities and threats, but a finite set (five to twenty) of the most important external factors should be included in the evaluation matrix. Note in the Dresser example that four key external threats and one key opportunity face the company in early 1984. Among the key factors included in the matrix, U.S. trade sanctions are most important to success in the industry, as indicated by a weighting of .35. This factor also represents Dresser's major threat as evidenced by a rating of 1 . A minor opportunity (rating $=3$ ) that Dresser could take advantage of in the future is 
large U.S. coal reserves. Note that Dresser's key external factors are (and should be) stated in specific terms. The total weighted score of 1.90 indicates that this company has a weak external strategic position. Dresser's weak external position could be a major reason why sales and profits have been declining yearly in the 1980's.

\section{Exhibit 6: A Sample External Factor Evaluation Matrix}

Dresser Industries, Inc.

Key External Factor

1. U.S. trade sanctions barring Dresser from supplying the Soviet Union and other foreign countries: 79\% of Dresser's net profit in 1983 came from operations in Europe.

2. In the petroleum industry, drilling expenditures declined nearly $50 \%$ percent between 1981 and 1983; 45\% of Dresser's revenues come from petroleum operations.

3. Oil prices are declining. They fell from $\$ 34$ per barrel to $\$ 29$ per barrel in 1983.

4. Turmoil in the Middle-East. Iran and Iraq are threatening to disrupt oil shipments from the Persian Gulf.

5. The U.S. coal market, which accounted for $50 \%$ of Dresser's mining sales in 1983, is booming.

TOTAL WEIGHTED SCORE

1.00

$\underline{1.90}$

Source: Based on Dresser's 1984 Annual Report and an article entitled "Dresser Industries: A Leaner Look as it Waits Out a Lingering Slump." Business Week, September 26, 1983, p. 78-79.

\section{Conclusion}

Due to increasing turbulence in business environments around the world, the external audit has become an explicit and complex part of the strategic management process (8). This article presents a new five-step approach for collecting and evaluating economic, social, political, technological, and competitive information. Firms that do not identify, monitor, forecast, and evaluate key environmental variables may fail to anticipate emerging opportunities and threats. This can lead to the pursuit of ineffective strategies. A 
major responsibility of strategists is to develop an effective external audit system. The external audit approach described in this article can be effectively used by any size or type of organization.

Matching environmental opportunities and threats with internal strengths and weaknesses provides the basis for successful strategy formulation (3). The Competitive Profile Matrix and External Factor Evaluation Matrix that are presented and exemplified in this article can help top managers identify and evaluate key environmental factors. Without the aid of analytical techniques, the external strategic management audit often becomes too subjective and general. However, the Competitive Profile Matrix and External Factor Evaluation Matrix should never be used indiscriminately, because intuitive judgments are always required in assigning weights and ratings. Good judgment and common sense is essential throughout the process of conducting an external strategic management audit.

\section{References}

1. Aaker, D.A. “Organizing A Strategic Information Scanning System." California Management Review, Vol. XXV, No. 2, January 1983, p. 76-83.

2. Brown, G.H. "The Impact of Demographic and Societal Changes on U.S. Business." Planning Review. Vol. 11, No. 3, May 1983, p. 32-39.

3. David F.R. FUNDAMENTALS OF STRATEGIC MANAGEMENT: CONCEPTS AND CASES. Columbus, Ohio: Charles E. Merrill Publishing Company, 1986, (in press).

4. David, F.R. Formulating Strategies Objectively: An Analytical Approach. Handbook of Business Strategy - 1985-1986 Yearbook. New York, N.Y.: Warren, Gorham, \& Lamont, November, 1985, (in press).

5. Diffenbach, J. "Corporate Environmental Analysis In Large U.S. Corporations." Long Range Planning. Vol. 16, No. 3, June 1983, p. 107-116.

6. Fella, J.W. "Capitalizing on Information in the Public Domain." Planning Review. March 1984, p. 34-38 \& 42.

7. Filho, P.V. "Environmental Analysis for Strategic Planning." Managerial Planning. January/February, 1985, p. 23-30.

8. Gluck, F. "Global Competition in the 1980's." Journal of Business Strategy. Spring 1983, p. 22-27.

9. Kresch, S.D. "The Impact of Consumer Trends on Corporate Strategy." Journal of Business Strategy. Winter 1983, p. 58-63.

10. McFarlan, F.W. "Information Technology Changes the Way You Compete." Harvard Business Review. May-June, 1984, p. 98-103.

11. Mesch, A.H. "Developing an Effective Environmental Assessment Function." Managerial Planning. Vol. 32, No. 5, March/April 1984, p. 17-22. 
12. Moyer, R. "The Futility of Forecasting." Long Range Planning. Vol. 17, No. 1, February 1984, p. 65-72.

13. Parsons, G.L. "Information Technology: A New Competitive Weapon." Sloan Management Review. Fall, 1983, p. 3-14.

14. Pearce, J.A. II and Robinson, R.B. Jr. "Environmental Forecasting: Key To Strategic Management." Business. July-September 1983, p. 3-12.

15. Porter, M. "Technology and Competitive Advantage." Journal of Business Strategy. Winter, 1985, p. 60-79.

16. Rhyne, L.C. "Strategic Information: The Key to Effective Planning." Managerial Planning. Vol. 32, No. 4, January/February 1984, p. 4-10.

17. Wiseman, C. and MacMillan, I.C. "Creating Competitive Weapons From Information Systems." Journal of Business Strategy. Fall, 1584, p. 42-50. 